\title{
N $89-22989$
}

MONOLITHIC SOLID OXIDE FUEL CELL DEVELOPMENT

\author{
K. M. Myles and C. C. McPheeters \\ Argonne National Laboratory \\ Argonne, Illinois
}

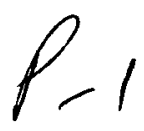

The Monolithic Solid Oxide Fuel Cell (MSOFC) is being developed by a recently formed team comprised of Argonne National Laboratory, Allied-Signal Aerospace/AiResearch, and Combustion Engineering. The MSOFC is an oxide-ceramic structure in which appropriate electronic and ionic conductors are fabricated in a "honeycomb" shape similar to a block of corrugated paperboard. The electrolyte that conducts oxygen ions from the air side to the fuel side is yttria-stabilized zirconia (YSZ). All the other materials are electronic conductors including the nickel-YSZ anode, the strontium-doped lanthanum manganite cathode, and the doped lanthanum chromite interconnect (bipolar plate). These electronic and ionic conductors are arranged to provide short conduction paths to minimize resistive losses. The power density achievable with the MSOFC is expected to be about $8 \mathrm{~kW} / \mathrm{kg}$ or $4 \mathrm{~kW} / \mathrm{L}$, at fuel efficiencies over $50 \%$, because of small cell size and low resistive losses in the materials. The MSOFC operates in the range of 700 to $1000^{\circ} \mathrm{C}$, at which temperatures rapid reform of hydrocarbon fuels is expected within the nickel-YSZ fuel channels.

Tape casting and hot roll calendering are used to fabricate the MSOFC structure. The tape casting process consists of spreading a ceramic slurry (slip) uniformly on a substrate, such as glass or polymer film, using a doctor blade. After the slip is dry, the ceramic layer is stripped off the substrate in the form of a flexible "tape." The hot roll calendering process consists of mixing ceramic powder with organic binder and plasticizer and rolling the warm mixture into a thin tape. The green tapes are cut to the desired dimensions, and the electrode tapes are corrugated to form the gas flow channels. The corrugations are formed by folding the tape onto a warm mold. After cooling, the tape retains the corrugated shape. Corrugated electrode tapes and flat electrolyte and interconnect composite tapes are stacked up to form the MSOFC structure. The layers are bonded together in the green state by heating the polymer binder slightly above its glass transition temperature under a small weight. The bonded green structure is then heated according to a precise firing schedule to the sintering temperature to form the monolithic ceramic structure.

The performance of the MSOFC has improved significantly during the course of development. The limitation of this system, based on materials resistance alone without interfacial resistances, is $0.093 \mathrm{ohm}-\mathrm{cm}^{2}$ area-specific resistance (ASR). The current typical performance of MSOFC single cells is characterized by ASRs of about 0.4 to $0.5 \mathrm{ohm}-\mathrm{cm}^{2}$. With further development the ASR is expected to be reduced below $0.2 \mathrm{ohm}-\mathrm{cm}^{2}$, which will result in power levels greater than $1.4 \mathrm{~W} / \mathrm{cm}^{2}$.

The feasibility of the MSOFC concept has been proven, and the performance has been dramatically improved. The differences in thermal expansion coefficients and firing shrinkages among the fuel cell materials have been minimized. As a result of good matching of these properties, the MSOFC structure has been successfully fabricated with few defects, and the system shows excellent promise for development into a practical power source. 